\title{
The efficacy of polyp detection and tumor characterization of blue laser imaging, blue light imaging, and linked color imaging with light-emitted diode (LED) and LASER endoscope
}

\author{
Naohisa Yoshida, Osamu Dohi, Ken Inoue, Yoshito Itoh \\ Department of Molecular Gastroenterology and Hepatology, Kyoto Prefectural University of Medicine, Graduate School of Medical Science, Kyoto, \\ Japan \\ Correspondence to: Naohisa Yoshida, MD, PhD. Department of Molecular Gastroenterology and Hepatology, Graduate School of Medical \\ Science, Kyoto Prefectural University of Medicine, 465 Kajii-cho, Kawaramachi-Hirokoji, Kamigyo-ku, Kyoto 602-8566, Japan. \\ Email: naohisa@koto.kpu-m.ac.jp. \\ Provenance and Peer Review: This article was commissioned by the Editorial Office, Annals of Translational Medicine. The article did not undergo \\ external peer review.
}

Submitted Dec 12, 2019. Accepted for publication Jan 16, 2020.

doi: $10.21037 /$ atm.2020.02.01

View this article at: http://dx.doi.org/10.21037/atm.2020.02.01

Colonoscopic resection of adenoma is reported to reduce the colorectal cancer incidence and death (1). However, standard observation of the colorectum using white-light imaging (WLI) causes polyp miss and its rate was reported to be $22 \%$ in a systematic review (2). Additionally, lots of patients receive surveillance colonoscopy due to the recent improvement of endoscopic resection and metachronous polyps should be detected and removed (3). Various researches have been performed to decrease polyp miss rate and increase adenoma detection rate (ADR) (4). However, image-enhanced endoscopy such as narrow band imaging (NBI) and flexible intelligence color enhancement (FICE) are not enough to improve these rates.

Novel endoscopes with a light-emitted diode (LED) light source (ELUXEO: 7000 systems in the West or 6000 series in Japan; Fujifilm, Tokyo, Japan) has been marketed since 2017-2018 in the world including the U.S., Europe, and Japan (5). LED endoscopes have $410 \mathrm{~nm}$-LED light and $450 \mathrm{~nm}$-LED light and multi-light technology provides high-quality images with blue laser imaging (BLI) as well as linked color imaging (LCI) for narrowband light observation (Figure 1) (6). BLI with or without magnification enables to detect surface pattern and vessel pattern of colorectal lesions clearly and is useful for tumor characterization. Additionally, BLI is made to improve tumor detection, making neoplastic lesions brownish. On the other hand, LCI has a bright view and makes neoplastic lesions appear reddish and this can be useful for tumor detection.

A LASER endoscopic system (LASEREO: Fujifilm Co., Tokyo, Japan) was marketed in 2012. Two laser lights, whose wavelength are 410 and $450 \mathrm{~nm}$ laser lights, and fluorescent light were used in this system and LASER endoscope enable us to perform BLI and LCI (Figure 1) (7-10). BLI makes lesions brownish and is useful for improving tumor detection, similar to BLI with LED endoscope. We previously reported that it improved polyp visibility more than WLI using endoscopists subjective polyp visibility score using videos (10). LCI is made using with the laser lights balance of same power value to BLI. LCI makes adenomatous polyps and inflammation appear more reddish and oppositely, it makes the surrounding mucosa around the lesions more whitish. So, the contrast between lesions and surrounding mucosa becomes high and lesions can be detected easily. Additionally, LCI is brighter than NBI and BLI and the residual liquid in the colorectum becomes reddish (11). Previously, we published a report that LCI could improve the diagnostic accuracy of atrophic gastritis due to the infection of Helicobacter pylori (12). A study showed that LCI improved the visibility of sessile serrated adenoma and polyps (SSA/P) and adenoma using videos and pictures compared to WLI and BLI (13). Additionally, our study showed that LCI was useful for improving detectability of SSA/P and flat neoplastic lesions 


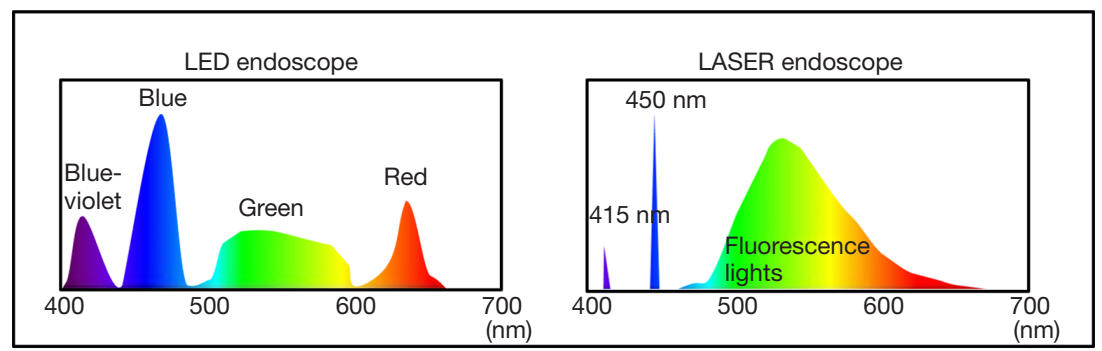

Figure 1 The comparison between LASER endoscope and LED endoscope. LED, light-emitted diode.

\begin{tabular}{|c|c|c|c|c|}
\hline & Type 1 & $\begin{array}{l}\text { Type 2A } \\
\text { (regular) }\end{array}$ & $\begin{array}{l}\text { Type 2B } \\
\text { (irregular) }\end{array}$ & $\begin{array}{c}\text { Type } 3 \\
\text { (destroyed) }\end{array}$ \\
\hline $\begin{array}{l}\text { Vessel } \\
\text { pattern }\end{array}$ & - Invisible & $\begin{array}{l}\text { - Regular caliber } \\
\text { - Regular } \\
\text { distribution } \\
\text { (meshed · spiral) }\end{array}$ & $\begin{array}{l}\text { - Variable caliber } \\
\text { - Irregular } \\
\text { distribution }\end{array}$ & $\begin{array}{l}\cdot \text { Loose vascular } \\
\text { area } \\
\cdot \text { Interruption of } \\
\text { thick vessel }\end{array}$ \\
\hline $\begin{array}{l}\text { Surface } \\
\text { pattern }\end{array}$ & $\begin{array}{l}\text { - Uniform dark or } \\
\text { white spots } \\
\text { - Similar to } \\
\text { surrounding } \\
\text { normal mucosa }\end{array}$ & $\begin{array}{l}\text { - Regular (tubular } \\
\text { branched · papillary) }\end{array}$ & $\begin{array}{l}\text { - Irregular or } \\
\text { unclear }\end{array}$ & - Amorphous \\
\hline $\begin{array}{l}\text { Typical } \\
\text { predicted } \\
\text { pathology }\end{array}$ & Hyperplastic polyp & $\begin{array}{l}\text { Adenoma with low } \\
\text { grade dysplasia }\end{array}$ & $\begin{array}{l}\text { High grade } \\
\text { dysplasia }\end{array}$ & $\begin{array}{l}\text { Deeply invasive } \\
\text { T1 cancer }\end{array}$ \\
\hline e 1 & & & & 3 \\
\hline
\end{tabular}

Figure 2 JNET classification for BLI magnification of LED endoscope (setting: EP-6000, EC-6600ZP). JNET, Japan NBI Expert Team; BLI, blue laser imaging; LED, light-emitted diode.

using endoscopic pictures (11). Moreover, our recent multicenter study proved the color difference $(\mathrm{CD})$ value as an objective indicator of adenoma for LCI was significantly higher than BLI (14). Oppositely, the CD value of SSA/ $\mathrm{P}$ was significantly higher in BLI than LCI. LCI also kept polyp visibility better than BLI and WLI, even with a 1.5-time faster withdrawal speed for observation than usual. We suggest this probably leads to faster observation and better polyp detection.

Regarding tumor characterization, NBI is used regularly in the world. Narrow-band imaging international colorectal endoscopic (NICE) classification is used for NBI without magnification and Japan NBI Expert Team (JNET) classification is used for NBI with magnification $(15,16)$. We previously reported NBI classification can be used for
BLI of LASER endoscope with magnification comparing the difference between NBI magnification and BLI magnification (8). Thus, NICE and JNET classification can be used for BLI magnification both of LASER and LED endoscope (Figure 2). We introduce the details described as follows. In the JNET classification, both vessel pattern and surface pattern have to be diagnosed. Type 1 indicates hyperplastic polyp (HP) and SSA/P; type 2A adenoma; type 2B high grade dysplasia, and type $3 \mathrm{~T} 1 \mathrm{~b}$ (Figure 3 ). Regarding SSA/P, dilated crypts and vessels are useful for BLI magnification of LASER and LED endoscopes to differentiate SSA/P from HP according to a previous paper though it was reported for NBI magnification (Figure 4) (17).

Recently, lots of reports have shown the efficacy of BLI and LCI in polyp detection (Table 1) (18-24). We 

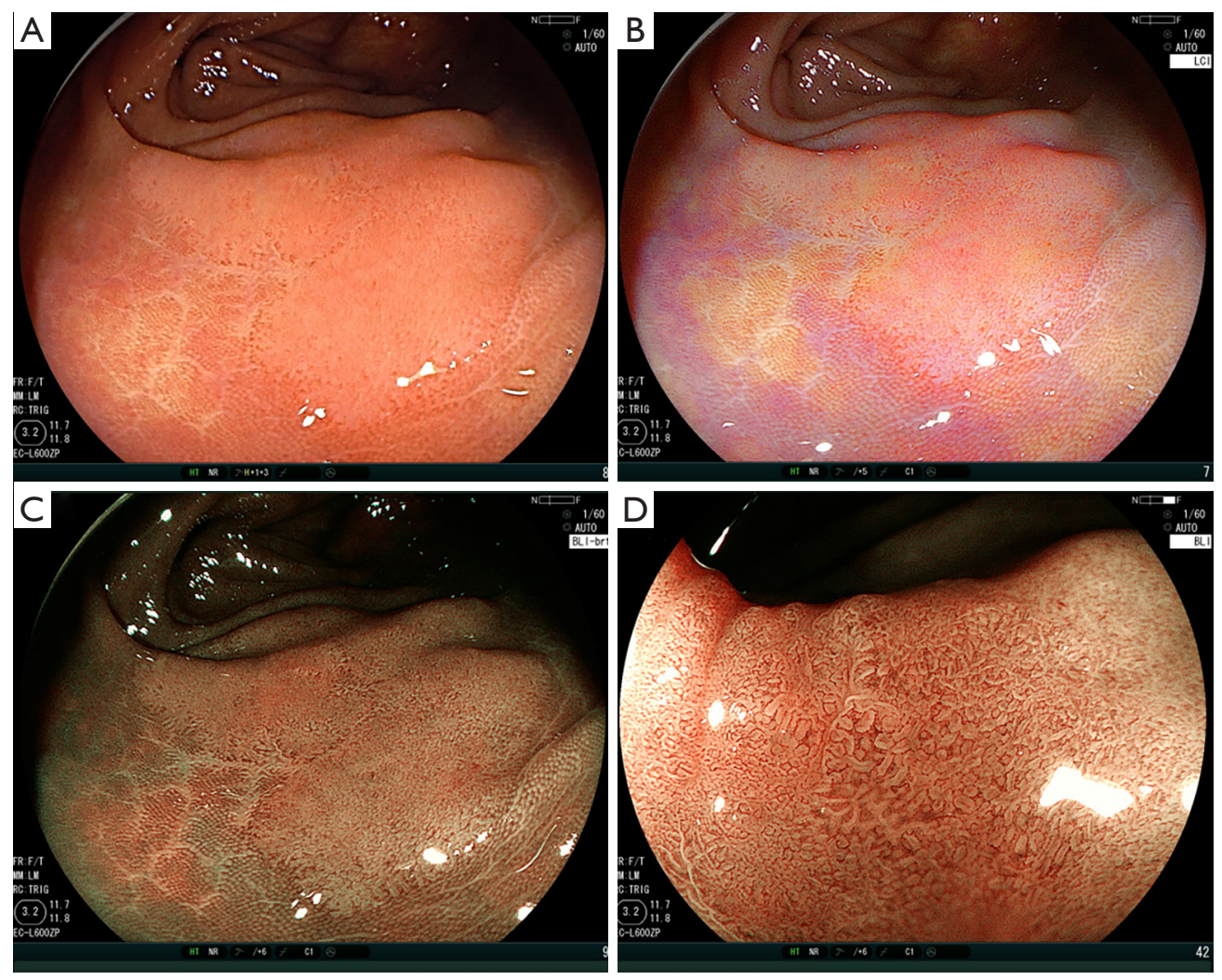

Figure 3 A case presentation of LASER endoscope with linked color imaging (LCI) and blue laser imaging (BLI). (A) White light imaging. Non-polypoid lesion, $20 \mathrm{~mm}$, Transvers colon. High-grade dysplasia; (B) LCI improves tumor detectability; (C) BLI improves tumor detectability; (D) BLI with magnification showed irregular pattern as JNET type 2B. JNET, Japan NBI Expert Team.

previously reported the efficacy of BLI for polyp detection in a multicenter study. It showed polyp number in BLI was significantly more than WLI and another study showed BLI improved polyp miss rate for right-sided colon $(18,19)$. However, residual liquid is reddish in BLI and it makes endoscopic views darker. A randomized control trial (RCT) with LASER endoscope from China in tandem endoscope proved that LCI increased sensitivity of polyp detection for the whole colorectum more than WLI (LCI vs. WLI: 73\% vs. 91\%, $\mathrm{P}<0.001)(20)$. A single-center RCT with LASER endoscope from Japan using a tandem endoscopy setting showed the SSA/P miss rate in WLI was significantly higher than that in LCI $(21.6 \%$ vs. $3.2 \%, \mathrm{P}=0.02$ ) (21). Additionally, a single-center RCT from Italy with LED endoscope showed LCI improved polyp miss rate significantly more than WLI in the rightsided colon (cecum and ascending colon) (11.8\% vs. 30.8\%, $\mathrm{P}<0.001)$ (22). Furthermore, we previously reported that an additional 30 -second observation for the cecum and ascending colon with LCI after initial WLI observation in LASER endoscope improved adenoma and SSA/P detection rate more than additional WLI observation after initial WLI observation (18.5\% vs. 6.2\%, $\mathrm{P}=0.03$ ) (23). A recent tandem RCT of LASER endoscope from Brazil about WLI, BLI, and LCI showed ADR of them were $43.2 \%$ vs. $54.0 \%$ vs. 56.9\%, (LCI vs. WLI, $\mathrm{P}=0.03$ ) (24). From the above points, we suggest LCI can be an appropriate tool for routine colonoscopic examination though there have been only limited reports from the limited area. However, we suggest LCI has a demerit about halation in an endoscopic observation because of its strong brightness, although this has not been analyzed before. Another possible demerit of LCI is about detectability of SSA/P. Because our previous multicenter study using an objective indicator using $\mathrm{CD}$ values showed the value for SSA/P about LCI was inferior than that about BLI in LASER endoscope $(17.2 \pm 7.5$ vs. 20.2 $\pm 9.2, \mathrm{P}=0.04$ ) (14). Further studies should be performed to prove and improve these points. 

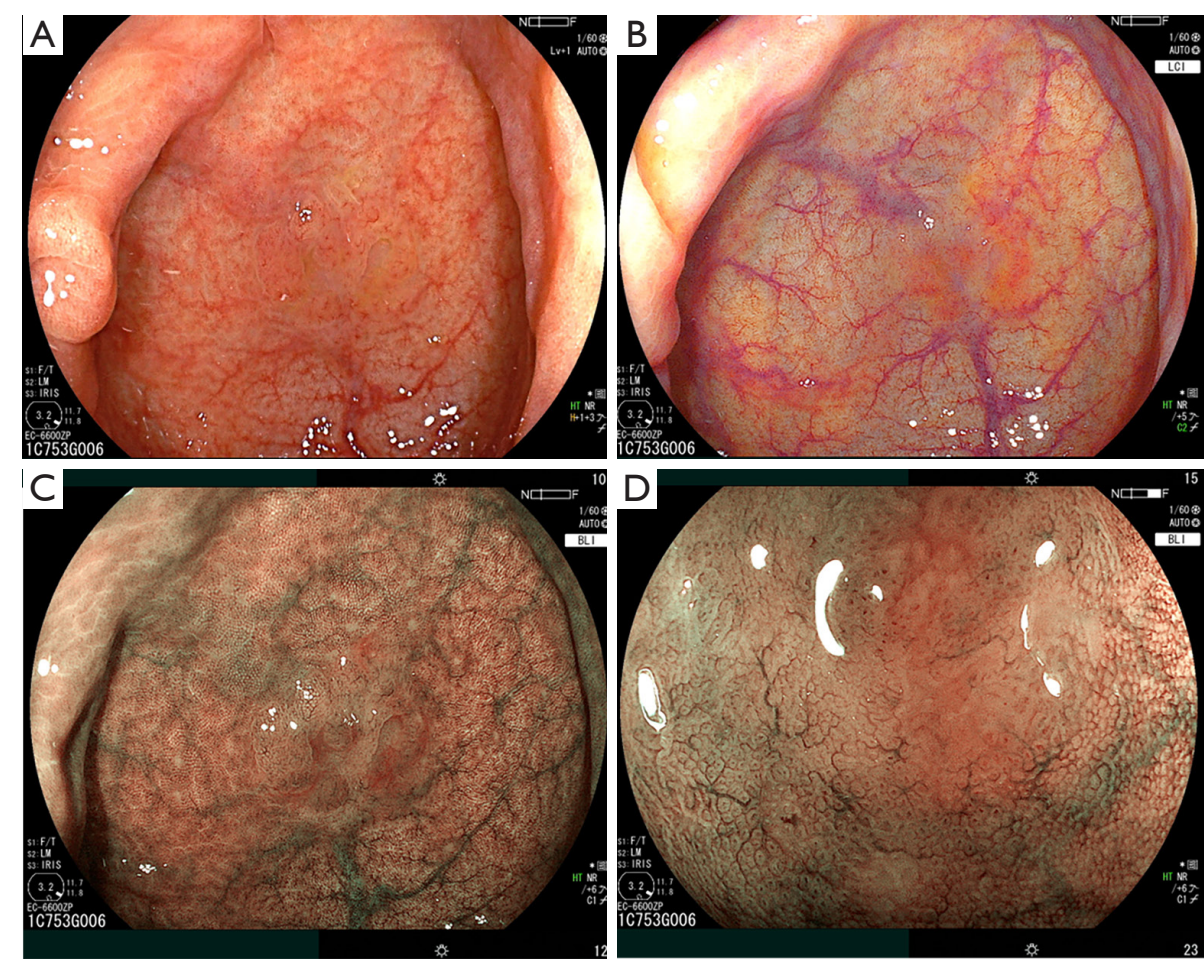

Figure 4 A case presentation of LED endoscope linked color imaging (LCI) and blue laser imaging (BLI). (A) White light imaging. Nonpolypoid lesion, $10 \mathrm{~mm}$, Cecum. High-grade adenoma; (B) LCI improves tumor detectability; (C) BLI improves tumor detectability; (D) BLI with magnification showed dilated crypts and dilated vessels. LED, light-emitted diode.

Table 1 Reports about tumor detection for BLI and LCI in LED and LASER endoscope

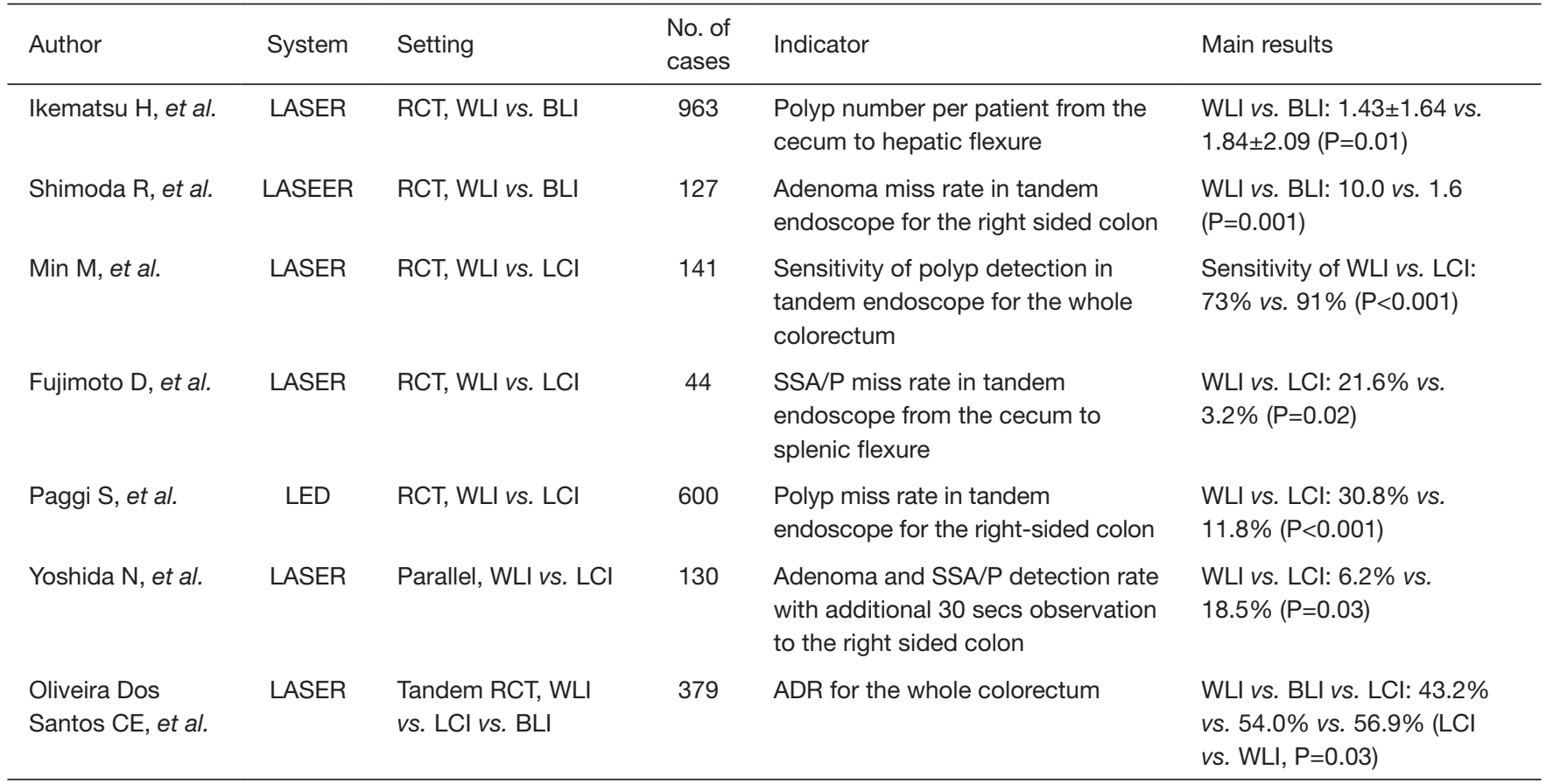

BLI, blue laser imaging; LCI, linked color imaging; RCT, randomized control trial; WLI, white-light imaging; SSA/P, sessile serrated adenoma and polyps; ADR, adenoma detection rate. 
In this editorial, we introduced the update of BLI and LCI for tumor characteristics and tumor detection in LASER endoscope and LED endoscope.

\section{Acknowledgments}

We thank all members of the Department of Molecular Gastroenterology and Hepatology, Kyoto Prefectural University of Medicine, for helping with this study.

Funding: None.

\section{Footnote}

Conflicts of Interest: $\mathrm{N}$ Yoshida and O Dohi received a research grant from FUJIFILM Medical Co., Ltd. The other authors have no conflicts of interest to declare.

Ethical Statement: The authors are accountable for all aspects of the work in ensuring that questions related to the accuracy or integrity of any part of the work are appropriately investigated and resolved.

Open Access Statement: This is an Open Access article distributed in accordance with the Creative Commons Attribution-NonCommercial-NoDerivs 4.0 International License (CC BY-NC-ND 4.0), which permits the noncommercial replication and distribution of the article with the strict proviso that no changes or edits are made and the original work is properly cited (including links to both the formal publication through the relevant DOI and the license). See: https://creativecommons.org/licenses/by-nc-nd/4.0/.

\section{References}

1. Zauber AG, Winawer SJ, O'Brien MJ, et al. Colonoscopic polypectomy and long-term prevention of colorectalcancer deaths. N Engl J Med 2012;366:687-96.

2. van Rijn JC, Reitsma JB, Stoker J. Polyp miss rate determined by tandem colonoscopy: a systematic review. Am J Gastroenterol 2006;101:343-50.

3. Fuccio L, Bhandari P, Maselli R, et al. Ten quality indicators for endoscopic submucosal dissection: what should be monitored and reported to improve quality. Ann Transl Med 2018;6:262.

4. Ishaq S, Siau K, Harrison E, et al. Technological advances for improving adenoma detection rates: The changing face of colonoscopy. Dig Liver Dis 2017;49:721-7.

5. Bisschops R, Hassan C, Bhandari P, et al. BASIC
(BLI Adenoma Serrated International Classification) classification for colorectal polyp characterization with blue light imaging. Endoscopy 2018;50:211-20.

6. Yoshida N, Dohi O, Inoue K, et al. Blue laser imaging, blue light imaging, and linked color imaging for the detection and characterization of colorectal tumors. Gut Liver 2019;13:140-8.

7. Osawa H, Yamamoto H. Present and future status of flexible spectral imaging color enhancement and blue laser imaging technology. Dig Endosc 2014;26 Suppl 1:105-15.

8. Yoshida N, Hisabe T, Inada Y, et al. The Ability of a Novel Blue Laser Imaging System for the Diagnosis of Invasion Depth of Colorectal Neoplasms. J Gastroenterol 2014;49:73-80.

9. Yoshida N, Yagi N, Inada Y, et al. The Ability of a Novel Blue Laser Imaging System for the Diagnosis of Colorectal Polyps. Dig Endosc 2014;26:250-8.

10. Yoshida N, Hisabe T, Hirose R, et al. Improvement in the visibility of colorectal polyps by using blue laser imaging. Gastrointest Endosc 2015;82:542-9.

11. Yoshida N, Naito Y, Murakami T, et al. Linked color imaging improves the visibility of colorectal polyps: a video study. Endosc Int Open 2017;5:E518-25.

12. Dohi O, Yagi N, Onozawa Y, et al. Linked color imaging improves endoscopic diagnosis of active Helicobacter pylori infection. Endosc Int Open 2016;4:E800-5.

13. Suzuki T, Hara T, Kitagawa Y, et al. Linked-color imaging improves endoscopic visibility of colorectal nongranular flat lesions. Gastrointest Endosc 2017;86:692-7.

14. Yoshida N, Hisabe T, Ikematsu H, et al. Comparison Between Linked Color Imaging and Blue Laser Imaging for Improving the Visibility of Flat Colorectal Polyps: A Multicenter Pilot Study. Dig Dis Sci 2019. [Online ahead of print].

15. Hayashi N, Tanaka S, Hewett DG, et al. Endoscopic prediction of deep submucosal invasive carcinoma: validation of the narrow-band imaging international colorectal endoscopic (NICE) classification. Gastrointest Endosc 2013;78:625-32.

16. Iwatate M, Sano Y, Tanaka S, et al. Validation study for development of the Japan NBI Expert Team classification of colorectal lesions. Dig Endosc 2018;30:642-51.

17. Yamashina T, Takeuchi Y, Uedo N, et al. Diagnostic features of sessile serrated adenoma/polyps on magnifying narrow band imaging: a prospective study of diagnostic accuracy. J Gastroenterol Hepatol 2015;30:117-23.

18. Ikematsu H, Sakamoto T, Togashi K, et al. Detectability of colorectal neoplastic lesions using a novel endoscopic 
system with blue laser imaging: a multicenter randomized controlled trial. Gastrointest. Endosc 2017;86:386-94.

19. Shimoda R, Sakata Y, Fujise T, et al. The adenoma miss rate of blue-laser imaging vs. white-light imaging during colonoscopy: a randomized tandem trial. Endoscopy 2017;49:186-90.

20. Min M, Deng P, Zhang W, et al. Comparison of linked color imaging and white-light colonoscopy for detection of colorectal polyps: a multicenter, randomized, crossover trial. Gastrointest Endosc 2017;86:724-30.

21. Fujimoto D, Muguruma N, Okamoto K, et al. Linked color imaging enhances endoscopic detection of sessile serrated adenoma/polyps. Endosc Int Open

Cite this article as: Yoshida N, Dohi O, Inoue K, Itoh Y. The efficacy of polyp detection and tumor characterization of blue laser imaging, blue light imaging, and linked color imaging with light-emitted diode (LED) and LASER endoscope. Ann Transl Med 2020;8(5):152. doi: 10.21037/atm.2020.02.01
2018;6:E322-34.

22. Paggi S, Mogavero G, Amato A, et al. Linked color imaging reduces the miss rate of neoplastic lesions in the right colon: a randomized tandem colonoscopy study. Endoscopy 2018;50:396-402.

23. Yoshida N, Inada Y, Yasuda R, et al. Additional Thirty Seconds Observation with Linked Color Imaging Improves Detection of Missed Polyps in the Right-Sided Colon. Gastroenterol Res Pract 2018;2018:5059834.

24. Oliveira Dos Santos CE, Malaman D, Pereira-Lima JC, et al. Impact of linked-color imaging on colorectal adenoma detection. Gastrointest Endosc 2019;90:826-34. 